\title{
The Ultra Structural Studies on Jejunum of Goat (Capra hircus)
}

\author{
Parveen Kumar Gahlot" and Pawan Kumar \\ Department of Veterinary Anatomy, Lala Lajpat Rai University of Veterinary and Animal Sciences, Hisar (Haryana), INDIA \\ *Corresponding author: PK Gahlot; E-mail: drparveen@hotmail.com
}

Received: 22 Oct., 2020

Revised: 22 March, 2021

Accepted: 25 March, 2021

\begin{abstract}
The tissues from the small intestine containing jejunum were collected from six young goats and processed for scanning and transmission electron microscopic studies. The jejunum villi were of different heights having a broad base with tapering to blunt ends. The surface of the villi showed slight corrugation in the initial part of the jejunum. These corrugations were very faint in this region and also showed orifices for goblet cells. The caudal segments of the jejunum showed some structural changes in the form of more prominent corrugations on the villi surface. The villi surface showed orifices with irregular boundaries for openings of goblet cells in between the dense areas of the microvilli. Whereas the transmission electron microscopy revealed that the epithelium of the jejunum was of a columnar type having goblet cells and no Paneth cells were observed in the villous part of the jejunum. A very few goblet cells were interspersed in between the columnar cells. The glandular epithelium consisted of different cell populations consisted of columnar, Paneth, endocrine and goblet cells.
\end{abstract}

\section{HIGHLIGHTS}

( The ultrastructural studies jejunum goat reveals the presence of long finger like villi with different cell population of enterochromaffin cells, Paneth cells and goblet cells.

Keywords: Jejunum, Enterochromaffin cell, Paneth cell, Scanning electron microscopy, Transmission electron microscopy

The jejunum being the longest segment of the small intestine plays an integral role in digestive and absorptive functions. There is a paucity of literature on the ultrastructure of the intestine of small ruminants including jejunum, except some work reported in goat (Hassan and Moussa, 2015). The present study was undertaken to study the ultrastructure of jejunum in goats which may be helpful in understanding the anatomy and mechanism of digestion and absorption in goats. Although histological studies on other species like sheep and goat were reported but ultra structural aspect was very scanty.

\section{MATERIALS AND METHODS}

The small intestine containing jejunum was collected from six young goats immediately after their sacrifice from the local slaughter house. The fresh tissues from selected sites of the jejunum of six goats were fixed in $2.5 \%$ glutaraldehyde solution for 6-8 hours after thorough washing with chilled $0.1 \mathrm{M}$ phosphate buffer $(\mathrm{pH} 7.4)$. The tissues were rewashed twice with $0.1 \mathrm{M}$ phosphate buffer and the rest of the procedure was carried out at EM Lab., A.I.I.M.S, New Delhi. The tissues were dehydrated in grades of ethanol, critical point dried and sputter-coated and the processed tissues were viewed in the scanning electron microscope (Zeiss EVO-18) to record observations and photographs of different jejuna segments.

For transmission electron microscopy, tissues from

How to cite this article: Gahlot, P.K. and Kumar, P. (2021). The ultra structural studies on jejunum of goat (Capra hircus). J. Anim. Res., 11(2) 311-315.

Source of Support: None; Conflict of Interest: None

(क) ब 
selected sites of the jejunum of six goats were primarily fixed in $2.5 \%$ glutaraldehyde solution and secondarily fixed in $2 \%$ osmium tetraoxide for one hour. The rest of the procedure was carried out at EM Lab., A.I.I.M.S, New Delhi. The ultrathin sections $(70-80 \mathrm{~nm})$ were stained with uranyl acetate and lead citrate. The processed tissues were viewed in the transmission electron microscope (Technai $\mathrm{G}^{2}$ ) to record observations and photographs of different jejuna segments

\section{RESULTS AND DISCUSSION}

\section{Scanning electron microscopy}

The mucosal surface of the jejunum had villi of variable height. The villi were having a broad base with tapering to blunt ends (Fig. 1a) as reported in the Egyptian goats (Hassan and Mousaa, 2015) where the villi were fingershaped with pointed apexes as reported in young pigs (Skrzypek et al., 2005), calves (Pearson et al., 1978; Po et al., 2005), dogs (Johnson et al., 1986) and humans (Marsh and Swift, 1969). These were long and flat in calves
(Dubourguier et al., 1978). Some villi were having inclined apexes probably due to more length of the ends. The surface of the villi showed slight corrugation in the initial part of the jejunum (Fig. 1b). These corrugations were very faint in this region and also showed orifices for goblet cells. The apex of the villi showed a scaly appearance with very few goblet cells as also reported in goats (Hassan and Moussa, 2015). There were 3-4 crypt openings surrounded each villus (Figs. 1a, 1b). As many as 20 crypts may surround each villus (Cocco et al., 1966), but a functional ratio of three crypts to one villus had been proposed in humans (Loehry and Creamer, 1969). The structural changes in the form of more prominent corrugations on the villi surface and density of villi were also increased towards the caudal aspect of the jejunum (Figs. 1c, 1d). The corrugations were deep, irregular clefts cutting into the side of the villus and dividing it into separate islands of tissue. The majority of these corrugations tended to run in a horizontal direction, similar observations were also reported in goats (Hassan and Mousaa, 2015).

Young pigs also showed a similar pattern in the form of transversal furrows (Skrzypek et al., 2005) and calves

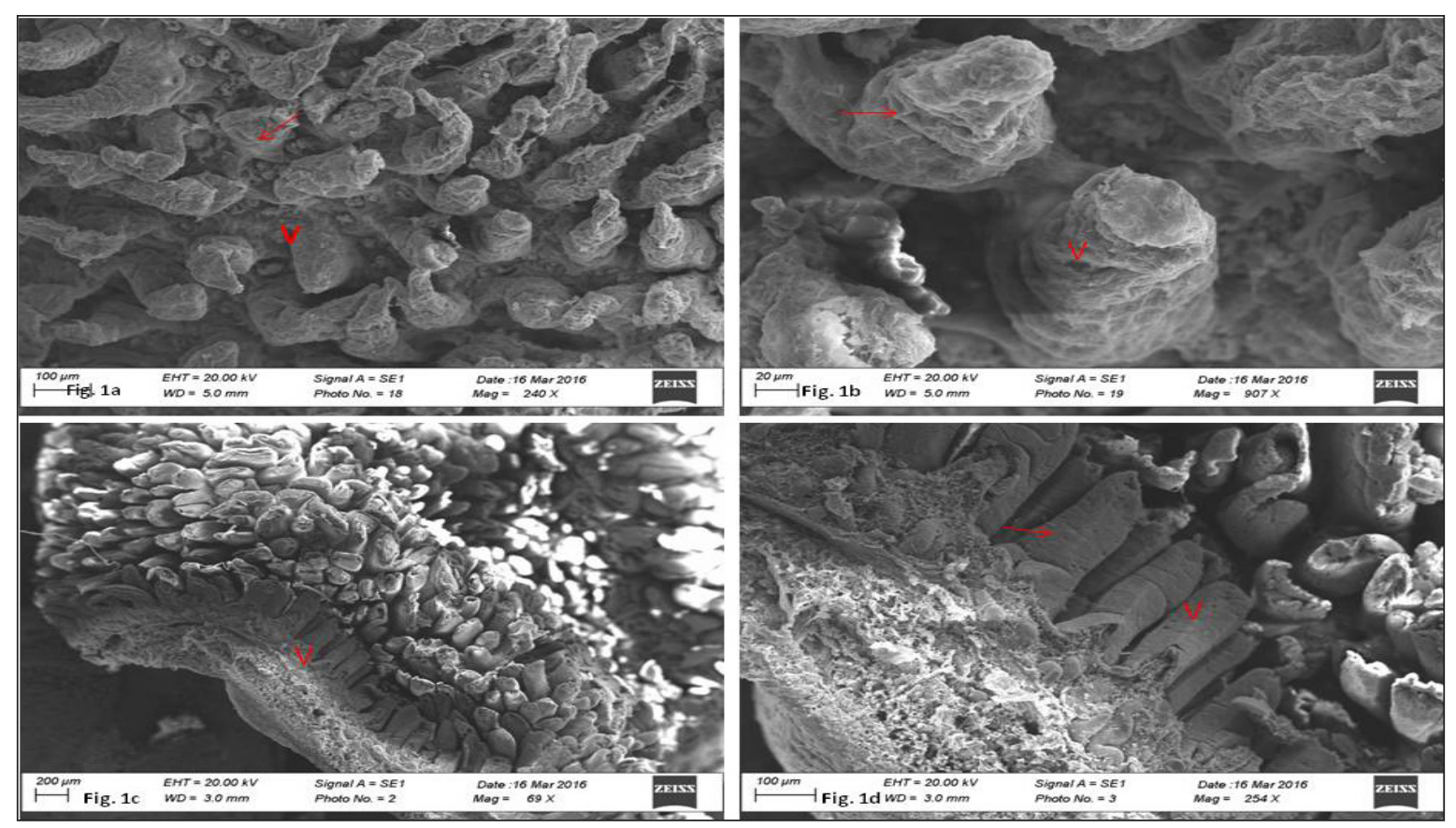

Fig. 1: Scanning electron micrograph of Jejunum of Goat. (a)Scanning electron micrograph showing villi (V) and crypts ( $\uparrow)$ on the mucosal surface of jejunum. $\times 240$; (b) Scanning electron micrograph showing jejunal villi (V) and faint corrugations $(\uparrow) . \times 907 ;(\mathbf{c})$ Scanning electron micrograph showing densely arranged jejunal villi $(V) . \times 69$; (d) Scanning electron micrograph showing fingershaped jejunal villi $(\mathrm{V})$ with faint corrugations $(\uparrow)$ on villi surface of jejunum. $\times 254$ 
(Dubourguier et al., 1978). The corrugations end abruptly and did not form a continuous system of clefts. At higher magnification, the villi surface showed hexagonal-shaped enterocytes and there was the presence of dense mat of microvilli throughout the villi surface (Figs. 2a, 2b) as observed in young pigs (Skrzypek et al., 2005). They also revealed that the villi surface had raised convex domeshaped structures at places towards the apex which were similar to the findings of the present study. At some regions where desquamation of upper surface took place presented the underlying submucosa and columnar cells were also seen in this region (Fig. 2c). The villi surface showed orifices with irregular boundaries for openings of goblet cells (Figs. 2b and 2d) in between the dense areas of the microvilli. There was the presence of some areas which were devoid of microvilli which were also observed in young pigs (Skrzypek et al., 2005). Towards the basal part of the villi, there was the presence of crypts or openings of intestinal glands.

\section{Transmission electron microscopy}

The epithelium of the jejunum was made up of columnar and goblet cells but no Paneth cells were observed in the villous part as reported in gnotobiotic dogs (Johnson et al., 1986). They also reported a single large or multiple moderate sizes, membrane-bound, supranuclear, cytoplasmic vacuoles. The columnar cells were with the well-marked microvilli (Figs. 3a and 3b). The microvilli contained a core made up of fine filaments forming thick bundles which extended deeply into the terminal web of the apical cytoplasm as reported in lambs (Gray et al., 1980) and mice (Mukherjee and Williams, 1967). The columnar cells were joined at the apical surface by typical junctional
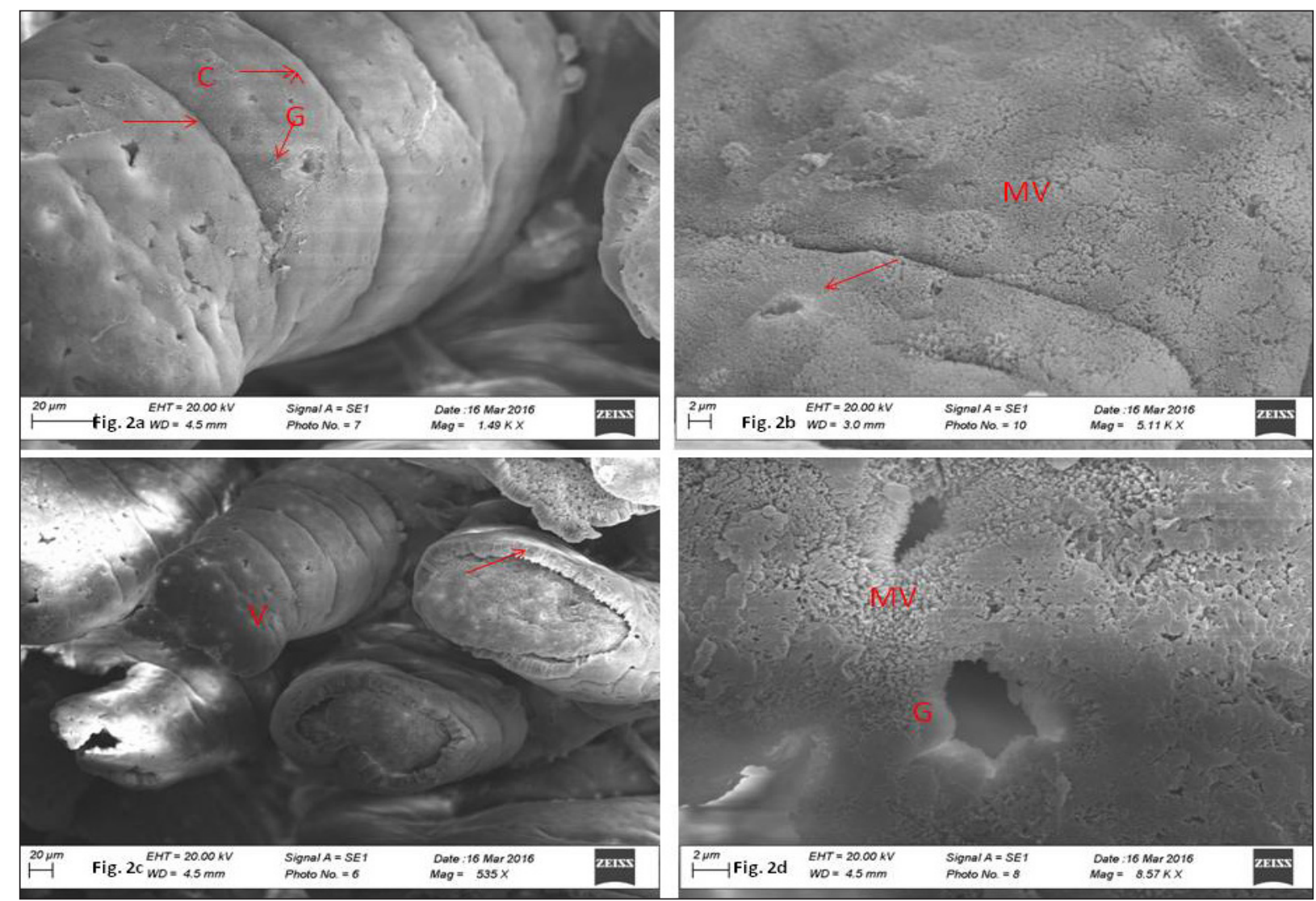

Fig. 2. (a) Scanning electron micrograph showing goblet cell opening $(G)$, corrugations $(C), F A E(\uparrow)$ on villi surface of jejunum. $\times$ 1490. (b) Scanning electron micrograph showing goblet cell opening ( $\uparrow$ ), dense mat of microvilli (MV) on villi surface of jejunum. $\times$ 5110. (c) Scanning electron micrograph showing columnar cell $(\uparrow)$ in jejunal villi $(V) . \times 535$. (d) Scanning electron micrograph showing the opening of goblet cell (G), dense mat of microvilli (MV) on villi surface of jejunum at higher magnification. $\times 8570$ 
complexes. The mitochondria of different shapes were abundant in number in the apical part of the cytoplasm (Fig. $3 b)$ and their size appeared to be slightly more as reported in gnotobiotic dogs (Johnson et al., 1986) and lambs (Gray et al., 1980). A very few goblet cells were interspersed in between the columnar cells. The cytoplasm of goblet cells was distended with mucus granules. The nucleus was located towards the base, granular endoplasmic reticulum and mitochondria were also present in the supranuclear part of the cytoplasm as observed in mice (Mukherjee and Williams, 1967).

The cryptal epithelium consisted of columnar, Paneth, endocrine and goblet cells. The columnar cells possessed luminal microvilli, nuclei placed towards the base and polymorphic mitochondria were as compared to the surface epithelial cells as reported in gnotobiotic dogs (Johnson et al., 1986). The microvilli appeared less numerous and short than those in enterocytes. The junctional complexes were also observed along with free ribosomes, Golgi bodies in the apical cytoplasm.
The Paneth cells were accumulated at the base of the crypts. They were pyramidal-shaped cells with their broad base resting on the basement membrane and narrowed towards the apical end. The osmiophilic granules located towards the apical portion of the cytoplasm also contained granular endoplasmic reticulum and Golgi bodies (Fig. $3 c)$ and this was in agreement with the findings in sheep (Ergun et al., 2003). The enterochromaffin cells were observed in the present study but their occurrence and number were decreased. These cells showed electrondense osmiophilic granules which were infranuclear in position in the cytoplasm (Fig. 3d) as reported in calves (Pearson and Logan, 1983) and other mammalian species (Dawson, 1970; Carvalheiar et al., 1968) and equine small intestine (Takehana et al., 1998) and several studies had been carried out in various animals (Satoh et al., 1990). The goblet cells were fewer in the epithelium of the crypts. They were generally flanked by the columnar cells through occasional goblet cells and Paneth cells were found. The cytoplasm was appeared dark as compared to the adjacent

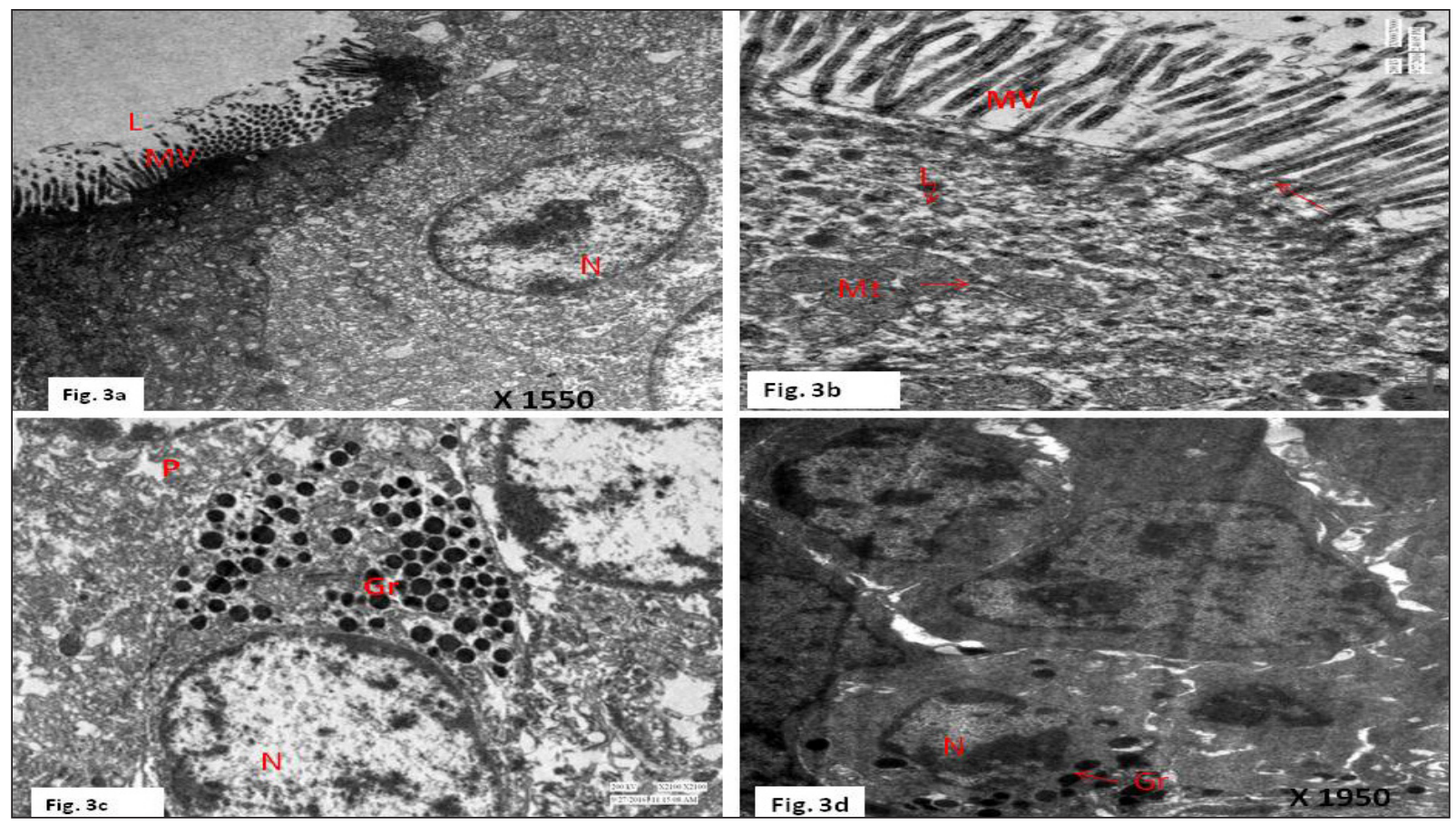

Figs. 3: Transmission electron micrography of goat Jejunum. (a)Transmission electron micrograph showing a columnar cell with microvilli (MV) towards Lumen (L) and nucleus (N). $\times 1550$; (b) Transmission electron micrograph showing microvilli (MV), terminal web $(\uparrow)$ in cytoplasm, lysosomes $(\mathrm{L})$ and mitochondria $(\mathrm{Mt})$ in jejunum. $\times 5000$; (c) Transmission electron micrograph showing Paneth cell (P) with osmiophilic granules (Gr) and nucleus $(\mathrm{N})$ in the cryptal epithelium of jejunum. $\times 2100$; (d) Transmission electron micrograph showing an enterochromaffin cell with osmiophilic granules $(\mathrm{Gr})$ and nucleus $(\mathrm{N})$ in the cryptal epithelium of jejunum. $\times 1950$ 
cells and their nucleus was pushed towards the base and granular endoplasmic reticulum and mitochondria were also observed as reported in humans (Kelley, 1973) and mice (Mukherjee and Williams, 1967). The goblet cells were scattered throughout the villus epithelium in lambs (Gray et al., 1980).

\section{CONCLUSION}

The scanning electron microscopy of jejunum showed mainly long slender finger-shaped villi with faint corrugation on the surface. The transmission electron microscopy showed the presence of simple columnar cells with a dense mat of microvilli in the surface epithelium. The cryptal epithelium was having Paneth, enterochromaffin and goblet cells.

\section{ACKNOWLEDGEMENTS}

Authors are thankful to Electron Microscopy Laboratory, All India Institute of Medical Sciences, New Delhi for their support.

\section{REFERENCES}

Carvalheiar, A.F., Welsch, U. and Pearse, A.G.E. 1968. Cytochemical and ultrastructural observations on the argentaffin and argyrophil cells of the gastrointestinal tract in mammals, and their place in the APUD series of polypeptidesecreting cells. Histochem., 14: 33-46.

Cocco, A.E., Dohrmann, M.J. and Hendrix, T.R. 1966. Reconstruction of normal jejunal biopsies: three-dimensional histology. Gastroenterol., 51: 24-31.

Dawson, I. 1970. The endocrine cells of the gastrointestinal tract. Histochem. J., 2: 527-549.

Dubourguier, H.C., Gouet, P.H., Mandard, O., Contrepois, M. and Bauhelehie C. 1978. Scanning electron microscopy of abomasum and intestine of gnotoxenic calves infected either with rota virus, corona virus or enteropathogenic Escherichia coli or with rota virus and E. coli. Ann. Rech. Vet., 9: 441-451

Ergun, E., Ergun, L., Asti, R.N. and Kurum, A. 2003. Light and scanning electron microscopic morphology of Paneth cells in the sheep small intestine. Revue Med. Vet., 154: 351-355.
Gray, E.W., Angus, K.W. and Snodgrass, D.R. 1980. Ultrastructure of the small intestine in astrovirus-infected lambs. J. Gen. Virolo., 49: 71-82.

Hassan, S.A. and Moussa, E.A. 2015. Light and scanning electron microscopy of the small intestine of goat (Capra hircus). J. Cell Anim. Biol., 9: 1-8.

Johnson, C.A., Snider, T.G., Henka, W.G. and Fulton, R.W. 1986. A scanning and transmission electron microscopic study of rotavirus-induced intestinal lesions in neonatal gnotobiotic dogs. Vet. Pathol., 23: 443-453.

Kelley, R.O. 1973. An ultrastructural and cytochemical study of developing small intestine in man. J. Embryol. Exp. Morph., 29: 411-430.

Loehry, C.A. and Creamer, B. 1969. Three dimensional structure of intestine in health and disease. Gut., 10: 6-12.

Marsh, M.N. and Swift, J.A. 1969. A study of the small intestinal mucosa using the scanning electron microscope. Gut., 10: 940-949.

Mukherjee, T.M. and Wynn Williams, A. 1967. A comparative study of the ultrastructure of the microvilli in the epithelium of small and large intestine of mice. J. Cell Biol., 34: $447-$ 461.

Pearson, G.R., Logan, E.F. and Brennan, G.P. 1978. Scanning electron microscopy of the small intestine of a normal unsuckled calf and a calf with enteric colibacillosis. Vet. Patholog., 15: 400-406.

Po Po, S., Zuki, A.B.Z., Zamri-Saad, M., Rahman-Omar, A. and Effendy, A.W. 2005. Morpholohical study of jejunal and ileal Peyer's patches of three month old calves. J. Anim. Vet. Adv., 4:579-589.

Satoh Y., Yamano, M., Matsuda, M. and Ono, K. 1990. Ultrastructure of Paneth cells in the intestine of various mammals. J. Electron. Microsc. Tech., 16: 69-80.

Skrzypek, T., Val Verde Piedra, J.L., Skrzypek, H., Wolinski, J., Kazimierczak, W., Szymanczyk, S., Pawlowska, M. and Zabielski, R. 2005. Light and scanning electron microscopy evaluation of the post natal small intestinal mucosa development in pigs. J. Physiol. Pharmacol., 56: 71-87.

Takehana, K., Masty, J., Yamaguchi, M., Kobayashi, A., Yamada, O., Kuroda, M., Park, Y.S., Iwasa, K. and Abe, M. 1998. Fine structural and histochemical study of equine Paneth cells. Anat. Histolog. Embryol., 27: 125-129. 
